\title{
Original Antide
}

\section{Podcast vs. Pamphlet; Which One Is More Effective in Self-care Training Program of Diabetic Patients?}

\author{
Mitra Zolfaghari ${ }^{1}$ Fatemeh Bahramnezhad $^{2 *}$ Parvaneh Alvandfar $^{3}$ Zahra Emami $^{3}$
}

1. Assistant Professor, Department of E-Learning. Virtual school, Tehran University of Medical Sciences, Center for Nursing Care Research (CNCR) Tehran University of Medical Sciences, Tehran, Iran

2. PhD in Nursing, Department of Critical Care Nursing, School of Nursing and Midwifery, Tehran University of Medical Sciences, Tehran, Iran

3. BSc, School of Nursing and Midwifery, Tehran University of Medical Sciences, Tehran, Iran.

*Correspondence to: Fatemeh Bahramnezhad

Bahramnezhad@razi.tums.ac.ir

\begin{abstract}
Background and Purpose: Self-care can help patients with diabetes to reduce complications of the disease. The purpose of this study was to compare the effectiveness of diabetes self-care educational programs through tow podcast and pamphlet methods.

Material and Methods: The present study was quasi-experimental research conducted in Tehran Aboozar Diabetes Center (2014). 90 patients with type II diabetes were selected and randomly divided into two groups of podcast training group $(n=45)$ and pamphlet group $(n=45)$. In both groups, the data were collected using the researcher-made questionnaire. In the podcast group, five audio training files were transferred via Bluetooth to the patients' mobiles, and the pamphlet group was given an educational pamphlet with a quite similar content. After 12 weeks, the two groups were assessed by the same questionnaire. The collected data was analyzed using SPSS Software, version 16, through statistical t-test at a significance level of $\mathrm{P} \leq 0.05$.

Results: The mean of adherence to exercise programs, drug treatment, and diabetic diet were 15.53, 23.92, and 48.20, respectively, for Podcast Group, while these values were 14.48, 24.04, and 46.54 for Pamphlet Group, respectively. After the intervention, the mean of adherence to exercise programs, drug treatment, and diabetic diet increased as follows: Podcast group (20.00, 23.95 and 57.12); Pamphlet group (21.26, 25.40 and 55.59).

Conclusion: The use of podcast such as pamphlet is recommended to increase the adherence rate of selfcare behaviors of diabetic patients. Due to the great satisfaction of patients with podcast, the method is suggested as an effective, simple, and attractive method to control diabetes and compliance with care practices.
\end{abstract}

Keywords: Diabetes; Auditory training; Pamphlet; Self-care; Podcast

Citation: Zolfaghari M, Bahramnezhad F, Alvandfar P, Emami Z, Podcast vs, Pamphlet. Which One Is More Effective in Selfcare Training Program of Diabetic Patients? Iran J Health Sci. 2017; 5 (2):1-10

Copyright (C) 2017, Published by Mazandaran University of Medical Sciences on behalf of Iranian Journal of Health Sciences and Health Sciences Research Center. This is an open-access article distributed under the terms of the Creative Commons Attribution-Non Commercial 4.0 International License https://creativecommons.org/licenses/by-nc/4.0/which permits copy and redistribute the material just in noncommercial usages, provided the original work is properly cited. 


\section{Introduction}

Diabetes is one of the most common chronic diseases around the world (1). It was predicted that the number of 151 million people with diabetes in the year 2000 would reach 221 million people in 2010 (2). Diabetes mellitus epidemic has affected all countries, both developed and developing ones (3). Several epidemiological studies conducted in Iran have reported the prevalence of diabetes and impaired glucose tolerance similar to or even slightly higher than its incidence in other parts of the world (4). In the year 2004, the prevalence of diabetes in the population range of 26 to 64 years old in district 17 of Tehran was reported to be $9.3 \%$ (5). Diabetes is considered as the second cause of patients' hospitalization and spending health costs. Increasing urbanization, changing lifestyles, and control of communicable diseases associated with changes in the age distribution of the population has caused Iran to be faced with an increasing prevalence and incidence of chronic non-communicable diseases including diabetes (6). It should be noted that diabetes has been recently introduced as a health priority in Iran, and its incidence is increasing (7). Type II diabetes is the most common form of this disease as it includes $90-95 \%$ of all cases of diabetes (3). It is expected that in the coming years, the prevalence of type II diabetes will experience an increased trend higher than type I diabetes due to increasing obesity and sedentary lifestyle (7).

Diabetes control means its prevention and delaying the causing complications (1). It includes five components of nutrition control, exercise, blood glucose measurement, medication, and patient education which is an essential component in the diabetes control process (8). According to the World Health
Organization's slogan, "Education is the basis of diabetes treatment", and education (training) has been recognized as the original basis and foundation of diabetes treatment (9). Diabetes control requires daily self-care in order to prevent serious complications of blindness, kidney disease, and neuropathy followed by amputation. All diabetics should be trained relevantly how to effectively deal with their disease (8). Despite the known benefits of diabetes self-care education programs, previous studies have shown a lack of knowledge in patients with diabetes unlike their continuous presence in specialized clinics or repeated hospitalizations (1). It has been documented that the use of distance education programs and audio technology in diabetic patients is a diverse experience and method which not only reduces additional costs but also is time saving (10). In recent years, the use of mobile technology has created a new revolution that is competing with the World Wide Web (11). Using the capabilities of mobile phones in education is considered as a new form of learning in the future (12). With regard to the educational role of a nurse in controlling chronic diseases, such as diabetes and the capabilities of "Mobile Learning" services, conducting a research to study the impact of mobile phone use in auditory learning on self-care behaviors of diabetic patients seems necessary. One of the advantages of using mobile phone is the possible use of recorded educational content at any place and time, repeating it wherever and whenever a patient desires, in addition to its quick and easy use (13). Given that providing a training pamphlet as a common and effective method of increasing the awareness level of diabetic patients has been demonstrated and emphasized in different studies conducted in Iran (14-16), and 
knowing that pamphlets are frequently provided to patients in the clinics, the present study attempted to investigate the effect of podcast (by Voice Recorder) in comparison with visual training (pamphlet) on self-care behaviors in type II diabetic patients.

\section{Materials and Methods}

The current research was a quasiexperimental study conducted in the year 2014. Among the patients in a diabetes center in Tehran (Aboozar Diabetes Center), 90 patients with type II diabetes were selected and randomly divided into two 'Podcast' $(\mathrm{n}=45)$ and 'Education by pamphlet' ( $\mathrm{n}=$ 45) groups by random tables. The study inclusion criteria included type II diabetes diagnosis by an endocrinologist physician (not requiring insulin), confirmation of not suffering from chronic diabetes complications by an endocrinologist physician, residency in Tehran, lack of formal education about diabetes, ability to read and write, having a personal mobile phone, having necessary knowledge concerning cell phone use, lack of podcast and vision problems, not suffering from psychological disorders, and physical problems or serious illnesses (such as liver failure, renal failure). Exclusion criteria, on the other hand, included hospitalization in a hospital for any reason during the study period, leaving Tehran during the study period, and unwillingness of the patient to continue cooperation. Sampling was carried out through continuous sampling method. Regarding self-care behavior rate, $\mathrm{P}$ value was equal to 0.5 , while the significance level enhanced to be $80 \%$ with $\alpha=5 \%$ (significance level of $95 \%$ ) and $\beta=20 \%$ ( $80 \%$ of power). Hence, the required sample size for each group was estimated to be 40 subjects. Also, due to the possibility of loss of $10 \%$ of the samples, the number of samples in each group was determined to be 45 cases. In the present study, the data was collected through the instrument of a questionnaire. The questionnaire consisted of three parts: Part I (11 questions) related to demographic characteristics, Part II (6 questions) related to disease characteristics, and Part III (38 questions) concerning adherence to treatment diet, with a minimum score of 3 or maximum score of 127 about the diet (19 questions with a minimum score of 0 and a maximum score of 76), sports (10 questions - with a minimum score of 2 and a maximum score of 36), and drug regimen (9 items - with a minimum score of 1 and the maximum score of 15). The total of the scores represented the adherence rate for self-care behaviors (127 points).

For tool validity, the content validity was used. Hence, after reading valid scientific books and literature, the questionnaire was prepared, which was provided to 10 experts and faculty members of Tehran University of Medical Sciences, and the necessary amendments were made to it. Also, to determine reliability, the test-retest method was used. Thus, the developed questionnaires was given to 15 non-eligible patients for study inclusion criteria who did not include the study samples and their scores were calculated. After two weeks, the questionnaires were again filled out by the same persons, and were approved using the Pearson correlation coefficient with the reliability of 0.92 .

The patients were evaluated at the beginning of the study and after 12 weeks using a selfreport questionnaire. For data collection and doing an intervention, the researchers attended Aboozar Diabetes Center in Tehran after obtaining the written agreement of the 
Vice Chancellor for Research and the Ethics Committee of Tehran University of Medical Sciences. First, the researchers introduced themselves to the center authorities explaining the aim of the study and providing their letter of introduction. After obtaining the permission to have access to the records of patients with diabetes, the researchers selected the patients according to their inclusion criteria. Then, the eligible patients were contacted to obtain their written informed consent to participate in the study. The patients were randomly divided into two groups by table of random table. The podcast group subjects were asked to bring their mobile phones with themselves before the beginning of the intervention. Before providing training information to the patients, some explanations were also provided in about 30 minutes regarding the research purpose, educational content, and the way to use it, as well as an emphasis which was put on listening to the learning content for arbitrary times during the study period (12 weeks). Then, five audio training files recorded by Jet Audio Software were edited using U Lead 16 Software and converted to MP3 format through Convertor Software. They included the following titles which were sent to the patients' mobile phones in podcast group via Bluetooth: Familiarity with diabetes (for 2 minutes with a size of $2.40 \mathrm{MB}$ ), diabetic diet (for 14 minutes with a size of 13.0 MB), drugs reducing blood glucose (for $3 \mathrm{~min}$, and the size of $2.85 \mathrm{MB}$ ), importance of exercise in diabetes (4-min and size of 3.94 $\mathrm{MB})$ and nursing recommendations required for the prevention of diabetes complications (a duration of 11 minutes and 32 seconds and the size of $10.05 \mathrm{MB}$ ). All patients were controlled regarding receiving five audio files and their correct playing. The patients in pamphlet group were invited to attend the diabetes center the following day. The same explanations were provided for this group for about 30 minutes in relation to the research purpose, educational content and emphasis on desired frequency of reading during the 12week period. Then, an educational pamphlet with educational content quite similar to audio files was given to them. Also, a contact phone number was provided to the entire subjects in both groups for asking possible questions or solving any problems regarding the instructions. After 12 weeks, all subjects were invited and re-evaluated through the same questionnaire. The rate of compliance with self-care behaviors before and after intervention was compared in both podcast and pamphlets groups. Also, after 12 weeks, the patients' satisfaction rate regarding the quality of educational content, the times of listening to the audio files, as well as the times of reading the pamphlets and their comments about the education method were all evaluated using the questionnaire. Data analysis was also performed using descriptive and inferential statistics, such as independent t-test and paired t-test through SPSS Software, version 16.

\section{Results}

In total, 5 patients were excluded from the study for reasons, such as unwillingness to continue cooperation, not being in Tehran, and hospitalization. Thus, the statistical analysis was performed on 85 patients (44 patients in pamphlet group and 41 subjects in podcast group). The patients studied in both groups were homogeneous regarding all demographic and clinical characteristics. The mean ages in aural training and pamphlet groups were 54.92 and 58.72 years old, respectively. More than a half of the subjects 
in both podcast (68\%) and pamphlet (70\%) groups were females. The average weights in the pamphlet and podcast groups were 70.72 $\mathrm{kg}$ and $75.78 \mathrm{~kg}$, respectively (Other demographic characteristics are shown in Table 1).

Table1. The demographic specifications of the studied units

\begin{tabular}{lllll}
\hline \multicolumn{2}{l}{ Characteristic demographic } & Podcast & Pamphlet & $\begin{array}{l}\text { Paired Samples } \\
\text { T- Test }\end{array}$ \\
\cline { 3 - 5 } Gender & Female & $34(68)$ & $\mathrm{N}(\%)$ & $\mathrm{P}<0.829$ \\
& Male & $16(32)$ & $15(70)$ & \\
Marital status & Single & $4(8)$ & $11(32)$ & $\mathrm{P}<0.05$ \\
& Married & $46(92)$ & $39(78)$ & \\
Job status & Jobless & $7(14)$ & $10(20)$ & $\mathrm{P}<0.569$ \\
& Housewife & $9(18)$ & $6(12)$ & \\
\multirow{5}{*}{ Educational level } & Employed & $34(64)$ & $34(68)$ & \\
& Illiterate & $17(34)$ & $22(44)$ & $\mathrm{p}<0.406$ \\
& Diploma & $24(48)$ & $23(46)$ & \\
Smoking & Diploma & $9(18)$ & $5(10)$ & $\mathrm{P}<0.505$ \\
& Yes & $6(12)$ & $4(8)$ & \\
\hline & No & $44(88)$ & $46(92)$ & \\
\hline
\end{tabular}

Before the intervention, the mean of adherence to exercise programs, drug treatment, and diabetic diet were calculated to be $15.53,23.92$, and 48.20 , respectively, in Podcast group, while the mean of adherence to the same factors in Pamphlet group were equal to $14.48,24.04$, and 46.54 , respectively. The independent t-test showed no significant difference between adherence to exercise programs, drug treatment, and diabetic diet in aural training and pamphlets groups before the intervention $(\mathrm{P}=0.265, \mathrm{P}=0.936$, and
$\mathrm{P}=0.523$ ). After the intervention, the mean of adherence to exercise programs, drug treatment and diabetic diet increased as follows: Podcast group (20.00, 23.95 and 57.12); Pamphlet group (21.26, 25.40 and 55.59). However, the results of independent $t-$ test showed no significant difference between the adherence rate to exercise programs, drug treatment, and diabetic diet in Podcast and Pamphlet groups $(\mathrm{P}=0.371, \mathrm{P}=0.319$ and $\mathrm{P}$ $=0.378$ ), as shown in Table 2 . 
Table2. Comparison of adherence to treatment (exercise, diet, and diabetic medications) before and after podcast intervention (via cell phone) and pamphlets

\begin{tabular}{|c|c|c|c|c|c|c|}
\hline Follow care & \multicolumn{2}{|c|}{ Groups } & Minimum & Maximum & Mean \pm SD & Paired Samples T- \\
\hline \multirow[t]{4}{*}{ Exercise } & \multirow[t]{2}{*}{ Pamphlet } & Before & 3 & 41 & $24.61 \pm 7.23$ & \multirow[t]{2}{*}{$\mathrm{P}<0.004$} \\
\hline & & After & 8 & 40 & $25.40 \pm 5.54$ & \\
\hline & \multirow{2}{*}{$\begin{array}{l}\text { Podcast } \\
\text { method }\end{array}$} & Before & 3 & 41 & $46.76 \pm 5.18$ & \multirow[t]{2}{*}{$\mathrm{P}<0.001$} \\
\hline & & After & 9 & 41 & $21.00 \pm 5.50$ & \\
\hline \multirow[t]{4}{*}{ Medication } & \multirow[t]{2}{*}{ Pamphlet } & Before & 11 & 64 & $46.18 \pm 8.41$ & \multirow[t]{2}{*}{$\mathrm{P}<0.198$} \\
\hline & & After & 14 & 71 & $55.59 \pm 7.27$ & \\
\hline & \multirow{2}{*}{$\begin{array}{l}\text { Podcast } \\
\text { method }\end{array}$} & Before & 13 & 67 & $48.78 \pm 6.10$ & \multirow[t]{2}{*}{$P<0.785$} \\
\hline & & After & 13 & 69 & $57.12 \pm 6.02$ & \\
\hline \multirow[t]{4}{*}{ Diabetic } & \multirow[t]{2}{*}{ Pamphlet } & Before & 25 & 41 & $24.61 \pm 7.48$ & \multirow[t]{2}{*}{$\mathrm{P}<0.000$} \\
\hline & & After & 38 & 40 & $25.40 \pm 7.50$ & \\
\hline & \multirow{2}{*}{$\begin{array}{l}\text { Podcast } \\
\text { method }\end{array}$} & Before & 35 & 41 & $23.80 \pm 7.19$ & \multirow[t]{2}{*}{$\mathrm{P}<0.000$} \\
\hline & & After & 35 & 41 & $23.95 \pm 8.42$ & \\
\hline
\end{tabular}

As shown in the table, it was revealed that both interventions were able to increase the rate of adherence to self-care behaviors (exercise programs, medications, and diabetic diet). The effectiveness of both interventions on the increased rate of adherence to self-care behaviors (exercise programs, medications, and diabetic diet) was not statistically significant. However, the paired t-test showed a statistically significant difference in adherence to exercise program and diabetic diet before and after the intervention in podcast group $(\mathrm{P}=0.001, \mathrm{P}=0.000)$. Also, in the pamphlet group, the difference was statistically significant $(\mathrm{P}=0.004, \mathrm{P}=0.000)$. On the other hand, the difference in medication adherence rates before and after intervention was not statistically significant in the Podcast group. Additionally, the difference was not statistically significant in the Pamphlet group $(\mathrm{P}=0.198)$. Given that the distribution was normal using Kolmogorov-Smirnov test, parametric tests (independent t-test, paired t-test, and chisquare test) were used for analyzing the data.

\section{Discussion}

The findings obtained from the current study showed that both podcast and written training interventions led to increased adherence to self-care behaviors of exercise program, medications, and diabetic diet. In the present study, after 12 weeks, the mean of adherence to exercise programs, drug treatment, and diabetic diet increased in the Podcast group to be 20.00, 23.95, and 57.12, respectively, while the Pamphlet group experienced the different values of $21.26,25.40$, and 55.59 regarding the same factors. The results of the independent t-test showed no significant difference between the levels of adherence to exercise program, drug treatment, and diabetic diet in auditory and pamphlet education groups after intervention, which means that both interventions were able to increase the rate of adherence to self-care behaviors (exercise program, medications and diabetic diet). The effectiveness of both interventions on the increased rate of adherence to self-care behaviors showed no statistically significant differences. Thus, it 
was found that using the mobile phone capability for podcast led to increased adherence to self-care behaviors similar to pamphlet use. Therefore, considering the patients' satisfaction rate of aural training in comparison with pamphlet method, the auditory teaching method is recommended as an effective, simple, attractive, and new methods for diabetes. It should be mentioned that despite many studies conducted in this regard, unfortunately, there was found almost no research on the effect of podcast and delivery of content in the form of audio files, and the present study could be the first attempt to investigate such an issue. For instance, the results of a study conducted by Sadeghi et al. (2011) regarding the comparison of verbal and written education impact on the anxiety of patients before surgery showed that both methods of verbal training (oral teaching in person) or written training (providing the instructional content by pamphlet) had significant differences as compared to the control group on the anxiety level of patients, but the difference between two teaching methods was not significant (17). Also, in a study conducted in Australia, Astley, et al. (2008) attempted to examine the impact of three different methods of providing information before coronary angiography on the rate of information recall, satisfaction, and anxiety of patients. Their findings showed that the types of audio/visual, written, and oral methods had no statistically significant differences regarding the above-mentioned variables; although, the anxiety rate in audio/visual group was reported to be slightly higher due to displaying details of medical procedures. Finally, Astley, et al. (2008) showed that the type of educational content could be effective in recalling information, not the method used to provide data (18). Research on adherence to treatment diet in diabetic patients has also confirmed the positive impact of education. The findings of a study done by Kim and $\mathrm{OH}$ (2003) on the effect of telephone follow-up by nurses on the adherence to diabetes control recommendations for 12 weeks showed a significant relationship between diet adherence $(p=0.006)$ and measurement of blood glucose $(\mathrm{p}=0.024)$ in two telephone follow-up and control groups (19). In their study, the education was based on patients' needs and telephone counseling provided by nurses, but in the present study, a preprepared educational content in audio file format was provided to the subjects. It should also be noted that in most of the studies conducted in European countries on diabetes education in recent years, all the capabilities of e-learning and multimedia are used to enrich the learning process $(20,21)$. However, due to bandwidth constraints and given that access to a computer connected to broadband in the current situation in Iran is not provided for all patients, replacing traditional methods with simple and yet effective methods could help to provide educational content to patients effectively, since "Education" is principally the basis of diabetes therapy and influences the adherence to diet therapy. In another study conducted by Wang et al., patients with diabetes education experiences, practice duration over one year or higher education level all had higher scores for KAP $(P<0.001, P<0.05$ and $P<0.001)$ than their colleagues, but after education, the patients' nutrition knowledge, awareness, and practice accuracy developed significantly $(P<0.05)(22)$. The findings of the present study were found to be consistent with the results of a study conducted by Gerber et al. (2005) on the effect of training diabetic 
patients with low health awareness through a multimedia computerized system in that the patients achieved a high level of awareness after the training. The comparison of patients' knowledge rate before and after training and during one year indicated a significant difference between the knowledge level before and after the training $(\mathrm{P}<0.001)(23)$. Shea et al.( 2006) compared the effect of education on knowledge and function levels in diabetic patients through telephone counseling and in person counseling methods during three months, and it was shown that the knowledge and performance levels of diabetic patients increased in both groups after intervention $(\mathrm{P}<0.01)$. However, there was no significant difference between the two groups. Also, the patients' satisfaction rate in the telephone counseling group had a greater increase in comparison with the in-person counseling group (from $22.8 \pm 8.6$ to $31.3 \pm$ 4.2) (24).

The study results regarding adherence to exercise program in two aural and pamphlet training groups by independent t-test showed significant statistical differences between adherence to exercise programs before and after the intervention. In line with the results of the current study, Kim et al. (2006) showed that after 12 weeks of intervention via short message service, there was a statistical significant difference $(\mathrm{P}=0.036)$ between the pre-intervention and post-intervention values in the group of diabetic patients (25). Also, in the study of Chan et al. (2005), a statistically significant difference $\quad(\mathrm{P}<0.01)$ was found between two internet intervention and control groups after the intervention regarding the amount of physical activity (1).The present study results regarding adherence to drug regimens also showed that there was no statistically significant difference between adherence to drug regimens in both groups before and after the intervention. The limitations of the current study included the possible lack of sufficient use of audio training files during 12 weeks by the subjects or neglecting their content. Although the present study attempted to draw the attention of the subjects, and requested their cooperation to focus on the educational audio files by explaining the research objectives, it was revealed that the amount and frequency of audio files use could not be controlled. Also, the self-care behaviors of patients could be influenced by other factors, such as encouragement from doctors, friends and healthcare workers. Through random allocation of subjects in two groups and measuring caring behaviors before and after intervention, the current study attempted to control such impacts, but due to the lack of a control group, it was observed that the aforementioned impacts could not be absolutely controlled. Therefore, it is recommended to repeat the research with more patients involved in the control group.

Overall, based on the research findings, it could be said that the use of different mobile phone capabilities, including downloading training files and using them for auditory education can lead to improved and increased compliance with self-care behaviors, and consequently, the prevention of complications due to diabetes can be expected. There were also found differences in the use of mobile capability between the present study and research conducted in other countries. In certain studies conducted overseas, the patients have played a more effective role and had a more active participation by using the Internet and sending SMS through mobile phones and the Internet. However, given that 
a large number of diabetic patients in Iran do not have access to the Internet, or lack the skills to use the Internet, other methods, such as using mobile phones, can be used for podcast to achieve the desired results.

\section{Acknowledgments}

This article is part of a research project approved by Tehran University of Medical Sciences(No.92-34-1260). The authors are grateful to the Vice-president of Research of Nursing and Midwifery Faculty of Tehran University of Medical Sciences and all those involved in this study.

\section{Conflict of interest}

The authors declare no conflict of interest in this research.

\section{References}

1. Chan WM, Woo J, Hui E, Lau WW, Lai JC, Lee D. A community model for care of elderly people with diabetes via telemedicine. Applied Nursing Research 2005;18:77-81. PMID: 15991104. DOI: 10.1016/j.apnr.2004.11.002

2. Keenan HA, Costacou T, Sun JK, Doria A, Cavellerano J, Coney J, et al. Clinical factors associated with resistance to microvascular complications in diabetic patients of extreme disease duration the 50-year medalist study. Diabetes Care 2007;30:1995-7. PMID: 17507696 DOI: $10.2337 / \mathrm{dc} 06-2222$

3. Liu X, Li C, Gong H, Cui Z, Fan L, Yu W, et al. An economic evaluation for prevention of diabetes mellitus in a developing country: a modelling study. BMC public health 2013;13:729. PMID:23919839 DOI: 10.1186/ 1471-2458-13-729

4. Alberti K, Eckel RH, Grundy SM, Zimmet PZ, Cleeman JI, Donato KA, et al. Harmonizing the Metabolic Syndrome A Joint Interim Statement of the International Diabetes Federation Task Force on Epidemiology and Prevention; National Heart, Lung, and Blood Institute; American Heart Association; World Heart Federation; International Atherosclerosis Society; and International Association for the Study of Obesity. Circulation 2009;120:1640-
5.DOI.org/10.1161/CIRCULATIONAHA.109. 192644

5. Larijani B, Mortazhajry S, Pourebrahim R, Noori $M$, Heshmat $R$, Shooshtarizadeh $P$. Assessment of type II diabetes \& FBS in inhabit of population between 25-64 in researcher group in Tehran medical university. Research in medicine journal 2003;24:2738(Persian).

6. Association AD. Diagnosis and classification of diabetes mellitus. Diabetes care 2008;31:S55-60. PMCID: PMC2797383 doi: $10.2337 / \mathrm{dc} 10-\mathrm{S} 062$

7. Maruthur NM. The growing prevalence of type 2 diabetes: increased incidence or improved survival? Current diabetes reports 2013;13:786-94. PMID:24072478 DOI:10.1007/s11892-013-0426-4

8. Gucciardi E, Fortugno M, Horodezny S, Lou W, Sidani S, Espin S, et al. Will Mobile Diabetes Education Teams (MDETs) in primary care improve patient care processes and health outcomes? Study protocol for a randomized controlled trial. Trials 2012;13:165. PMID:22974080 DOI: 10.1186/ 1745-6215-13-165

9. Haas L, Maryniuk M, Beck J, Cox CE, Duker $\mathrm{P}$, Edwards L, et al. National standards for diabetes self-management education and support. Diabetes care 2013;36:S100-8. http://dx.doi.org/10.2337/dc12-1707

10.Klonoff DC. Diabetes and Telemedicine Is the technology sound, effective, cost-effective, and practical? Diabetes Care 2003;26:1626-8. PMID:12716831

11.Free C, Phillips G, Galli L, Watson L, Felix L, Edwards $\mathrm{P}$, et al. The effectiveness of mobilehealth technology-based health behaviour change or disease management interventions for health care consumers: a systematic review. PLoS medicine 2013;10: 362-6. http:// dx.doi.org/10.1371/journal.pmed.1001362

12.Cochrane TD. Exploring mobile learning success factors. Research in Learning Technology 2010;18: 45-49. DOI: 10.1080/09687769.2010.494718

13. Martin S, Diaz G, Sancristobal E, Gil R, Castro M, Peire J. New technology trends in education: Seven years of forecasts and convergence. Computers \& Education 2011;57:1893-906.

Doi:10.1016/j.compedu.2011.04.003 
14.Sedigi J, Vahdaninia M, Khodabandeh A, Jaroondi F. Effect of Pamphlet on improving knowledge. Payesh 2004;4:29-38(Persian).

15.Karimi A, Mozafari F, Kamaledini H, Jokar S. The effectiveness of therapeutic exercises and general care by educational pamphlet on reduction of neck pain. Journal of Research in Rehabilitation Sciences 2004;6:1-10(Persian).

16.Amirnejad H, Khalilian S, Assareh MH, Ahmadian M. Estimating the existence value of north forests of Iran by using a contingent valuation method. Ecological Economics 2006;58:665-75. http:// dx.doi.org/10.1016/ j. ecolecon.2005.08.015

17.Sadeghi R. Effect of two type of education: verbal and pamphlet on pre-operation anxiety. Article of Ghazvin University of Medical Sciences 2011;1:24-8(Persian).

18.Astley CM, Chew DP, Aylward PE, Molloy DA, De Pasquale CG. A randomised study of three different informational AIDS prior to coronary angiography, measuring patient recall, satisfaction and anxiety. Heart, Lung and Circulation 2008;17:25-32. PMID: 17553747 DOI:10.1016/j.hlc.2007.04.008

19.Kim HS, Oh JA. Adherence to diabetes control recommendations: impact of nurse telephone calls. Journal of advanced nursing 2003;44:256-61. PMID:14641395

20.Azar M, Gabbay R. Web-based management of diabetes through glucose uploads: has the time come for telemedicine? Diabetes research and clinical practice 2009;83:9-17. PMID:19056140 DOI:10.1016/j. diabres. 2008.09.055
21.Ralston JD, Hirsch IB, Hoath J, Mullen M, Cheadle A, Goldberg HI. Web-based collaborative care for type 2 diabetes a pilot randomized trial. Diabetes care 2009;32:234-9. PMID:19017773 DOI:10.2337/dc08-1220

22.Wang H, Song Z, Ba Y, Zhu L, Wen Y. Nutritional and eating education improves knowledge and practice of patients with type 2 diabetes concerning dietary intake and blood glucose control in an outlying city of China. Public health nutrition 2014;17:2351-8. PMID:24124930 DOI: 10.1017/ S1368980013002735

23. Gerber BS, Brodsky IG, Lawless KA, Smolin LI, Arozullah AM, Smith EV, et al. Implementation and evaluation of a lowliteracy diabetes education computer multimedia application. Diabetes care2005;28: 1574-80. PMID: 15983303

24. Shea S, Weinstock RS, Starren J, Teresi J, Palmas W, Field L, et al. A randomized trial comparing telemedicine case management with usual care in older, ethnically diverse, medically underserved patients with diabetes mellitus. Journal of the American Medical Informatics Association 2006;13:40-51. PMID:1939009 DOI:10.1197/jamia.M3157

25.Kim H-S, Kim N-C, Ahn S-H. Impact of a nurse short message service intervention for patients with diabetes. Journal of nursing care quality 2006;21: 266-71. PMID:16816608. 